\title{
Neurogenic pulmonary edema following intracranial coil embolization for subarachnoid hemorrhage
} -A case report-

\author{
Jeong Eun Kim, Ji Hye Park, Sung Hyun Lee, and Yoonki Lee \\ Department of Anesthesiology and Pain Medicine, College of Medicine, The Catholic University of Korea, Seoul, Korea
}

Neurogenic pulmonary edema (NPE) is a well-known complication of acute central neurologic injury, particularly aneurysmal subarachnoid hemorrhage. Both increased intracranial pressure and severe over-activation of the sympathetic nervous system seem to be pathogenetic for the onset of NPE. Although intracranial endovascular therapy is minimally invasive, it may affect brain stem regions and result in sympathetic activation. We now report the case of a 70-year-old woman who suddenly developed pulmonary edema during coil embolization of a ruptured aneurysm. During the intervention, oxygen saturation declined suddenly and a chest radiograph revealed pulmonary edema. The delayed appearance of NPE in this patient implies a risk for sympathetically mediated NPE during endovascular therapy. (Korean J Anesthesiol 2012; 63: 368-371)

Key Words: Endovascular procedure, Pulmonary edema, Subarachnoid hemorrhage.

Pulmonary edema can be defined as abnormal accumulation of extravascular liquid in the lungs. It leads to impaired gas exchange and may cause respiratory failure. Acute pulmonary edema can also occur in patients with brain injury, and it is called neurogenic pulmonary edema (NPE). NPE is an acute life-threatening complication associated with many forms of central nervous system injury, such as brain or spinal cord hemorrhage, trauma, tumors, epilepsy, or infections [1-4]. NPE usually appears within minutes to hours after injury and has a high mortality rate if not recognized and treated appropriately [3].
Detachable coil embolization of intracranial aneurysms has proved to be a safe and effective treatment. It has been shown to produce superior survival over craniotomy and clipping for selected ruptured intracranial aneurysms [5]. Despite the minimally invasive nature of this procedure, NPE has previously been reported during endovascular therapy complicated by subarachnoid hemorrhage (SAH) $[6,7]$.

We now report a case of a patient undergoing coil embolization who suddenly developed pulmonary edema.

Received: June 29, 2011. Revised: 1st, July 28, 2011; 2nd, August 25, 2011. Accepted: August $29,2011$.

Corresponding author: Yoonki Lee, M.D., Department of Anesthesiology and Pain Medicine, College of Medicine, The Catholic University of Korea, Seoul Saint Mary's Hospital, 505, Banpo-dong, Seocho-gu, Seoul 137-701, Korea. Tel: 82-2-2258-6152, Fax: 82-2-537-1951, E-mail: yklee@ catholic.ac.kr

(C)This is an open-access article distributed under the terms of the Creative Commons Attribution Non-Commercial License (http:// creativecommons.org/licenses/by-nc/3.0/), which permits unrestricted non-commercial use, distribution, and reproduction in any medium, provided the original work is properly cited. 


\section{Case Report}

A 70-year-old woman with a history of hypertension for 10 years was found comatose in the bathroom. The patient was about $150 \mathrm{~cm}$ tall, and weighed $50 \mathrm{~kg}$. On arrival at the emergency department, her Glasgow Coma Scale was 6 and her vital signs were blood pressure $160 / 100 \mathrm{mmHg}$, heart rate 65 beats/min, and oxygen saturation $91 \%$. Her pupils were fixed with sluggish reaction to light. Her trachea was intubated by emergency physicians and the lungs were mechanically ventilated. Respiratory parameters included a tidal volume of $400 \mathrm{ml}$, a respiratory rate of 15 breaths/min, and an inspired oxygen concentration $\left(\mathrm{FiO}_{2}\right)$ of $100 \%$. A chest radiograph showed right bronchial intubation and subsegmental atelectasis in the left lower lung field. The tracheal tube then was withdrawn about $3 \mathrm{~cm}$. Her electrocardiogram (ECG) showed a prolonged QT interval and arterial blood gas analysis yielded a $\mathrm{pH}$ value of 7.42 , a partial carbon dioxide pressure $\left(\mathrm{PCO}_{2}\right)$ of $26.8 \mathrm{mmHg}$, a partial oxygen pressure $\left(\mathrm{PO}_{2}\right)$ of $303 \mathrm{mmHg}$, a base excess of -5.1 , an $\mathrm{HCO}_{3}$ concentration of $17.8 \mathrm{mmol} / \mathrm{L}$, and an oxygen saturation of $99.3 \%$.

Computed tomography of her brain showed global cerebral edema and massive SAH with intraventricular hemorrhage, corresponding to Fisher's grade 4 (Fig. 1). Computed tomographic angiography showed a saccular aneurysm involving the distal portion of the basilar artery. Clinically, the patient was presented as Hunt and Hess grade 5. An emergency intracranial detachable coil embolization and external ventricular drainage were planned.

Four hours from the beginning of mechanical ventilation, the patient arrived at the intervention room for intracranial endo-

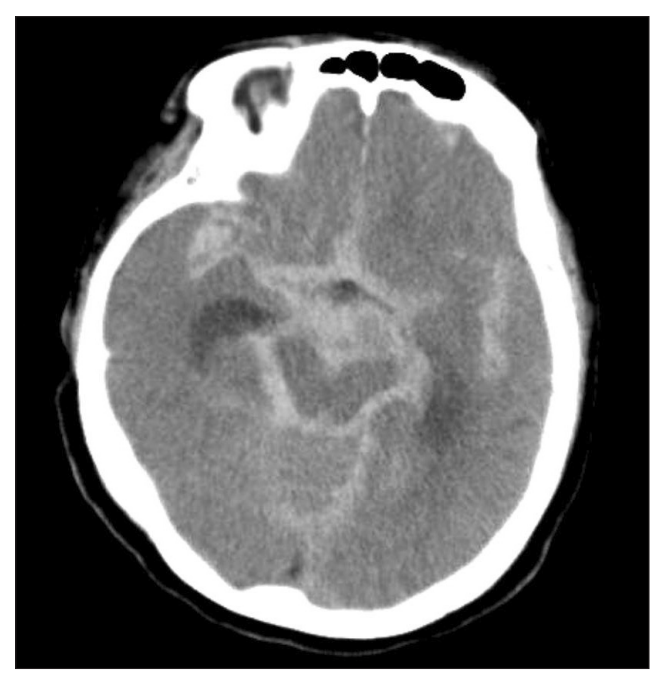

Fig. 1. Computed tomography imaging of the brain reveals a massive subarachnoid hemorrhage and intraventricular hemorrhage. vascular therapy. Standard monitors were put in place and her endotracheal tube was connected to the anesthetic machine. Blood pressure was $111 / 78 \mathrm{mmHg}$, heart rate was 82 beats/ min, and oxygen saturation was $100 \%$. Anesthesia was induced with thiopental $200 \mathrm{mg}$ and rocuronium $50 \mathrm{mg}$, and an arterial catheter was inserted in the right radial artery. Anesthesia was maintained with isoflurane $0.6-1$ vol\% with air $2.5 \mathrm{~L} / \mathrm{min}$ and $\mathrm{O}_{2} 1.5 \mathrm{~L} / \mathrm{min}\left(\mathrm{FiO}_{2}=50 \%\right)$. The end tidal $\mathrm{CO}_{2}\left(\mathrm{ETCO}_{2}\right)$ partial pressure was monitored by capnogram and maintained at $30-$ $35 \mathrm{mmHg}$.

The coil embolization was successfully performed after 2 hours. Immediately following the endovascular procedure, oxygen saturation was suddenly decreased to $93 \%$ and peak inspiratory pressure was increased to $22 \mathrm{cmH}_{2} \mathrm{O}$. Her blood pressure was increased to $153 / 85 \mathrm{mmHg}$ and heart rate was 85 beats/min. The location of the endotracheal tube was confirmed by auscultation and mild crackle was heard in both lung fields. In addition, a pink frothy secretion was suctioned through the endotracheal tube. Arterial blood gas analysis demonstrated a $\mathrm{pH}$ value of $7.39, \mathrm{PCO}_{2}$ of $30.2 \mathrm{mmHg}, \mathrm{PO}_{2}$ of $72.8 \mathrm{mmHg}$, and saturation of $93.8 \%$ while the patient's lungs were ventilated with $100 \%$ oxygen. Pulmonary edema was suspected, and chest radiography showed diffuse bilateral infiltrates (Fig. 2). The patient had received $500 \mathrm{ml}$ of normal saline and urine output was $300 \mathrm{ml}$ during the procedure.

She was then brought to the operating room for external ventricular drainage for treatment of hydrocephalus. On arriving at the operating room, blood pressure was $143 / 75 \mathrm{mmHg}$, heart rate was 83 beats/min, and oxygen saturation was $95 \%$. Anesthesia was maintained with sevoflurane 1 to 1.5 vol\% with $\mathrm{O}_{2} 5 \mathrm{~L} / \mathrm{min}$. A central venous catheter was inserted in the

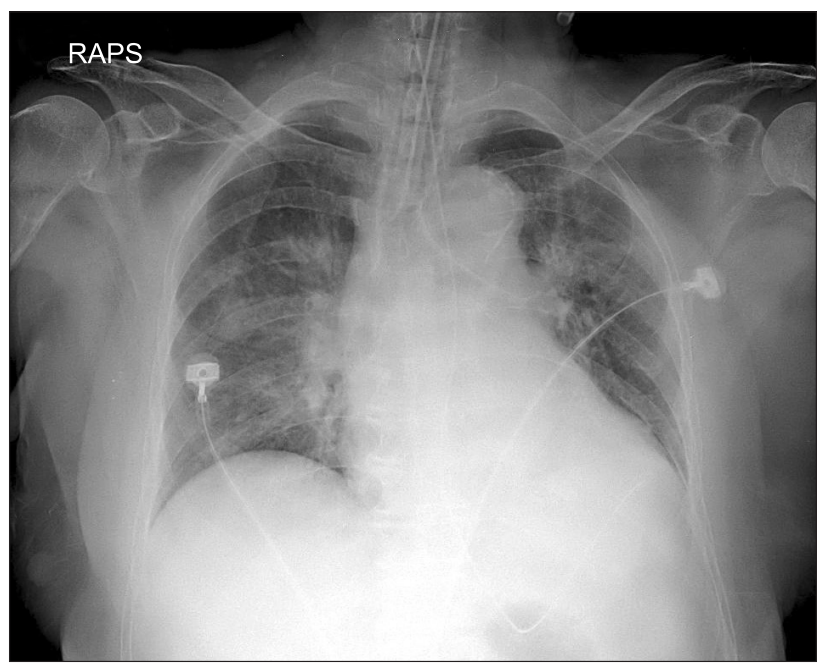

Fig. 2. Chest radiograph shows diffuse bilateral infiltrates in the lung indicating the presence of pulmonary edema. 
left subclavian vein by surgeon and the initial central venous pressure was $7 \mathrm{mmHg}$. The pulmonary edema was treated with intravenous $10 \mathrm{mg}$ of furosemide and a positive end expiratory pressure (PEEP) of $10 \mathrm{cmH}_{2} \mathrm{O}$.

External ventricular drainage produced bloody cerebrospinal fluid and the initial intracranial pressure (ICP) was about 15 $\mathrm{mmHg}$ (normal intracranial pressure $=7$ to $15 \mathrm{mmHg}$ ). Forty five minutes after application of PEEP with $100 \%$ oxygen and external ventricular drainage, her oxygen saturation increased to $100 \%$. The overall anesthetic time was four hours and the patient received 1,200 $\mathrm{ml}$ of normal saline and had a urine output of 1,400 ml.

The patient was admitted to the intensive care unit for pharmacologic and ventilatory support. An immediate postoperative arterial blood gas analysis showed a $\mathrm{pH}$ value of 7.37, $\mathrm{PCO}_{2}$ of $32.5 \mathrm{mmHg}, \mathrm{PO}_{2}$ of $99.3 \mathrm{mmHg}$, and oxygen saturation of $97 \%$. Postoperative echocardiography showed preserved left ventricle systolic function (left ventricle ejection fraction $=65 \%$ ) and no significant segmental wall motion abnormalities. Within 72 hours, her respiratory status improved with a resolution of the pulmonary edema (Fig. 3). However, her consciousness level was not improved and she was transferred to another hospital for conservative management after a prolonged hospital stay.

\section{Discussion}

NPE occurs in $8-23 \%$ of patients with SAH $[3,8]$. The incidence of NPE was significantly higher in patients with clinically and radiologically severe bleeding and in those with a ruptured aneurysm in the posterior cerebral circulation, leading to an acute rise of ICP in the vicinity of the medulla oblongata [8].

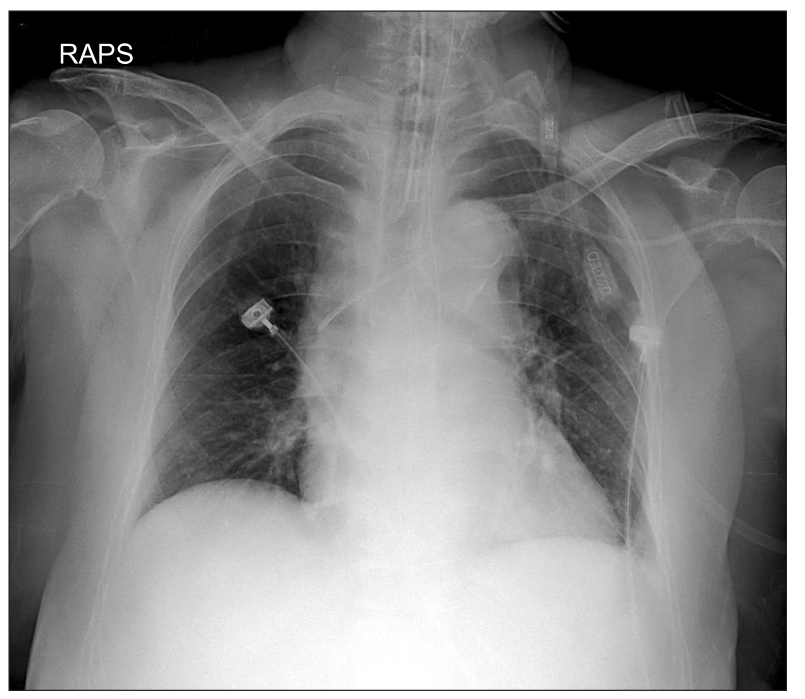

Fig. 3. Chest radiograph shows resolution of the pulmonary edema at postoperative day 3 .
Patients with NPE have a high mortality rate, likely due to the severe grade of the bleeding [8].

The clinical symptoms for NPE are nonspecific and often include dyspnea, tachypnea, tachycardia, cyanosis, pink frothy sputum, crackles, and rales on physical examination. The chest radiograph shows bilateral infiltrates and a normal-sized heart [1-4].

The differential diagnoses include aspiration pneumonia, ventilator-associated pneumonia, and ventilator induced pulmonary injury. For this patient, myocardial ischemia or pulmonary embolism was also assumed. However, pulmonary edema was occurring shortly after SAH and there were no signs of a primary cardiovascular event, no ECG changes, and no suspicion of aspiration. Therefore, NPE was diagnosed.

Although several pathophysiologic mechanisms have been implicated in the development of NPE, the exact cascade leading to its development remains unclear. Either a sudden increase of ICP or localized ischemic insult of certain brain trigger zones (hypothalamus and medulla) seem to be pathogenetic for the onset of NPE $[3,9,10]$. A sudden increase in ICP induces an $\alpha$-adrenergic catecholaminergic response, which, in turn, causes transient but dramatic increases in both pulmonary and systemic vasoconstriction in the veins or arteries. The resultant striking increase in pulmonary vascular pressure causes an alteration of the Starling forces in the lungs, with a subsequent shift of fluid into the pulmonary alveoli and the interstitial spaces.

It is not clear whether the NPE in this case was caused by changes in ICP or by sympathetic stimulation induced by intracranial endovascular manipulation. Muroi et al. [8] showed that elevated ICP values were found in $67 \%$ of the patients with NPE and the ICP values of the other $33 \%$ of the patients did not increase. It is suggested that NPE can occur without elevated ICP, even though increased ICP is an important risk factor for developing NPE.

In this case, her ICP checked during external ventricular drainage was high, but within the normal range. In addition, her lungs were hyperventilated during external ventricular drainage $\left(\mathrm{PaCO}_{2}=30.2\right.$ to $\left.32.5 \mathrm{mmHg}\right)$. Considering these facts, the possibility of NPE is present, although the ICP did not increase.

During endovascular procedure, cerebral artery may be distended or pulled by catheter or guide wire manipulation. Brewer and Borel [7] demonstrated that endovascular balloon inflation might affect brain stem regions regulating sympathetic outflow and contribute to the development of NPE. The location of the bleeding source and bleeding pattern in correlation with the medulla oblongata is important, because stimulation of the medulla is essential for reactive sympathetic activation [8]. In this case, NPE was developed immediately after coil embolization of aneurysm at the basilar artery which was near 
the medulla. And oxygen saturation was suddenly decreased accompanied by an increase in arterial blood pressure (reached 153/85 mmHg from baseline 111/78 $\mathrm{mmHg}$ ). For these reasons, it must be considered that the endovascular manipulation of coil embolization might result in sympathetic stimulation and eventually develop NPE.

The management of NPE is based on the rapid control of the triggering central neurologic insult and prompt reduction in intracranial pressure. It is also based on conventional treatment of pulmonary edema $[3,4]$. Tracheal intubation, controlled ventilation with supplemental oxygen, moderate PEEP, and diuresis are essential in optimization of pulmonary status. PEEP values lower than $15 \mathrm{cmH}_{2} \mathrm{O}$ have been shown not to impede the cerebral perfusion pressure [11]. Depending on the severity of the primary insult, NPE may resolve in 48-72 hours with appropriate treatment, and patient prognosis is then dependent on the neurologic injury [12]. In this case, the patient received external ventricular drainage implantation, ventilator support with PEEP, and pharmacologic therapy. As a result, oxygen saturation increased rapidly and the respiratory status was recovered within 72 hours. However, her mental status was not improved.

This is a report of NPE following an endovascular coil embolization for SAH. The combination of a central neurologic insult and the endovascular procedure likely led to the NPE. If not recognized and treated appropriately, NPE can lead to acute cardiopulmonary failure with consequent global hypoperfusion and hypoxia. Therefore, awareness of and knowledge about the occurrence, clinical presentation, and treatment of NPE is essential.

\section{References}

1. Rogers FB, Shackford SR, Trevisani GT, Davis JW, Mackersie RC, Hoyt DB. Neurogenic pulmonary edema in fatal and nonfatal head injuries. J Trauma 1995; 39: 860-6.

2. Ahrens J, Capelle HH, Przemeck M. Neurogenic pulmonary edema in a fatal case of subarachnoid hemorrhage. J Clin Anesth 2008; 20: 129-32.

3. Baumann A, Audibert G, McDonnell J, Mertes PM. Neurogenic pulmonary edema. Acta Anaesthesiol Scand 2007; 51: 447-55.

4. Pender ES, Pollack CV Jr. Neurogenic pulmonary edema: case reports and review. J Emerg Med 1992; 10: 45-51.

5. Cross DT 3rd. Endovascular treatment for cerebral aneurysms will replace clipping. J Neurosurg Anesthesiol 2003; 15: 58-60.

6. Quader K, Manninen PH, Lai JK. Pulmonary edema in the neuroradiology suite: a diagnostic dilemma. Can J Anaesth 2001; 48: 30812.

7. Brewer RP, Borel CO. Neurogenic pulmonary edema during intracranial endovascular therapy. Neurocrit Care 2004; 1: 423-7.

8. Muroi C, Keller M, Pangalu A, Fortunati M, Yonekawa Y, Keller E. Neurogenic pulmonary edema in patients with subarachnoid hemorrhage. J Neurosurg Anesthesiol 2008; 20: 188-92.

9. Novitzky D, Wicomb WN, Rose AG, Cooper DK, Reichart B. Pathophysiology of pulmonary edema following experimental brain death in the chacma baboon. Ann Thorac Surg 1987; 43: 288-94.

10. Simon RP. Neurogenic pulmonary edema. Neurol Clin 1993; 11: 309-23.

11. McGuire G, Crossley D, Richards J, Wong D. Effects of varying levels of positive end-expiratory pressure on intracranial pressure and cerebral perfusion pressure. Crit Care Med 1997; 25: 1059-62.

12. Gruber A, Reinprecht A, Görzer H, Fridrich P, Czech T, Illievich UM, et al. Pulmonary function and radiographic abnormalities related to neurological outcome after aneurysmal subarachnoid hemorrhage. J Neurosurg 1998; 88: 28-37. 